\title{
Apresentação
}

\section{Trabalhadores, sindicatos e a transnacionalização da militância}

MAURÍCIO ROMBALDI"

KIMI TOMIZAKI

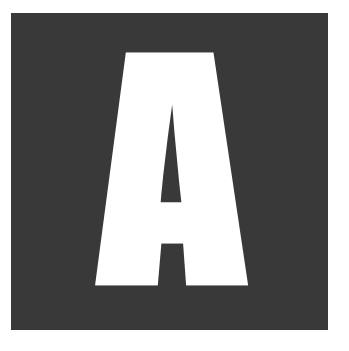

ideia da internacionalização da luta contra o capital é parte marcante da história do movimento operário. A organização transnacional de trabalhadores não se restringe à atualidade, mas corresponde a um investimento político que remete às Internacionais Comunistas ocorridas no século XIX, as quais se constituíram como "eixo central do programa histórico de emancipação da classe trabalhadora" (Löwy, 1989). Desde a virada do século XXI, no entanto, a militância transnacional tem progredido substancialmente, por meio da elaboração de novas estratégias direcionadas para além dos padrões de mobilização e negociação tradicionalmente estabelecidos no nível nacional. Isso pode ser observado mediante uma série de estudos que tem apontado para o aumento do número de campanhas sindicais articuladas globalmente, visando à promoção de melhores condições de trabalho e a celebração de acordos ${ }^{1}$

\footnotetext{
* Universidade Federal da Paraíba, Brasil

** Universidade de São Paulo, Brasil.

${ }^{1}$ Desde os anos 2000, de modo geral, as federações sindicais internacionais estabeleceram a quase totalidade de seus acordos internacionais junto a ETNs. As exceções residem em acordos com empresas alemãs, os quais foram assinados antes disso, devido às particularidades das relações sindicais desses casos.
} 
junto a Empresas Transnacionais (ETNs) (Anner et al., 2014; Evans, 2014; Gray, 2009; Keida, 2006).

O crescimento da supraterritorialidade do capital está associado à busca pela ampliação de mercados, por menores custos com mão de obra, taxação e regulação, bem como pelas possibilidades de movimentação do capital produtivo ou financeiro, que passa a se comprometer e descomprometer com crescente rapidez e menos sanções (Chesnais, 1996; Scholte, 1997). Uma das principais consequências desse fenômeno é observada nos processos de reestruturação dos conglomerados industriais e no expressivo aumento do número de Empresas Transnacionais (ETNs) em escala mundial (UNCTAD, 2008).

Nesse contexto, as atuais reações sindicais de alcance transnacional têm buscado se constituir como um padrão da militância que coloca em curso práticas políticas de caráter multifacetado. Tais práticas têm se voltado à construção de agendas que ultrapassam as demandas nacionais e se materializam de diferentes formas, sejam as redes globais de trabaIhadores por empresa, os acordos internacionais ou, ainda, as campanhas organizadas em torno de temas diretamente relacionados à defesa de direitos dos trabalhadores.

No Brasil, o impulso à liberalização da economia durante a década de 1990 resultou em processos de reestruturação produtiva e em uma proliferação de ETNs, que implicaram múltiplas redefinições das estratégias sindicais. No paradigma produtivo precedente, de modo geral, os sindicatos estavam habituados a negociar nacionalmente, seja com governos e empresas do país, seja com empresas estrangeiras administradas por gerências locais com autonomia limitada. Nos últimos anos, inúmeras ETNs que atuam no Brasil também se tornaram alvo de estratégias sindicais que ultrapassam as fronteiras nacionais. Este foi o caso de empresas como a estadunidense Walmart, a espanhola Prosegur e a chilena Arauco, 
ou mesmo das transnacionais de origem brasileira que passaram a intensificar sua presença fora do país, com Gerdau, Vale, Odebrecht, entre outras. Além disso, o país tem se destacado por sediar grandes eventos esportivos, como a Copa do Mundo de Futebol e as Olimpíadas de 2016, que também são objeto de campanhas sindicais globais, com resultados expressivos para as organizações locais (Rombaldi, 2014). Em todos esses casos, as Federações Sindicais Internacionais (FSIs) desenvolveram campanhas que visavam à melhoria de condições de trabalho, à regulamentação do trabalho migrante, ao combate a práticas antissindicais ou ao ajuste de acordos específicos, por empresa. No que tange ao caso brasileiro, é preciso sublinhar uma importante circulação de sindicalistas locais, de diferentes categorias profissionais, em FSIs, nas quais esses têm ocupado posições de destaque na definição das políticas sindicais de caráter transnacional (Rombaldi, 2012; 2016; Tomizaki, 2013).

A despeito da emergência da transnacionalização da organização de trabalhadores no plano empírico, pesquisadores do tema divergem quanto à potencialidade dos resultados alcançados até o momento e às perspectivas sobre o futuro do sindicalismo. Análises mais otimistas reconhecem que, apesar do enfraquecimento do poder de barganha dos trabalhadores, incapazes de se reorganizarem espacialmente frente à hipermobilidade do capital, o desenvolvimento capitalista não ocorreu com a sua passividade (Sylver, 2005; Evans, 2014). Nesse ponto de vista, a dinâmica capitalista, que não se restringe a fronteiras nacionais, teria, até certo ponto, possibilitado e estimulado a emergência de novas formas de organização sindical em regiões aparentemente mais vulneráveis aos interesses do capital. No mesmo sentido, o surgimento de ETNs poderia exprimir a constituição de novos mapas corporativos, que conectariam trabalhadores de diferentes regiões do planeta. Há ainda autores, como Anner (2014), para os quais as particularidades setoriais são fundamen- 
tais para o freio ou o impulso à elaboração de ações articuladas entre organizações de trabalhadores de diferentes países. Para ele, isso implica, sobretudo, distintas potencialidades para a internacionalização sindical. Adotando um tom mais pessimista, Burawoy (2010) assume a perspectiva de que o capitalismo seria continuamente capaz de suplantar as possibilidades de contra movimento, o que colocaria dúvidas sobre a potencialidade da transnacionalização da militância como um investimento capaz de assegurar avanços para o movimento operário.

Outras perspectivas indicam que a correlação de forças entre trabaIhadores e empresas está submetida a uma crescente precarização das relações de trabalho, o que estaria resultando em uma "sociedade da terceirização total" (Antunes, 2015). Em um ambiente em que a flexibilização e a precariedade das relações de trabalho se intensificam como fenômeno global, a constituição das classes sociais e as possibilidades de organização seriam cada vez mais movediças. A esse respeito, Standing (2013) discorre sobre um contexto em que trabalhadores não teriam "âncoras de estabilidade" capazes de oferecer visões de longo prazo. Isso implicaria sérias dificuldades aos sindicatos e às suas tradicionais formas de mobilização, diante do desafio de organizar o precariado, uma classe social heterogênea, carente do senso de "memória social" e de solidariedade.

Nesse contexto, uma série de questões relativas à organização dos trabalhadores em escala global desafia as lentes sociológicas, dada a complexidade de uma atuação política, por princípio, multifacetada. Partindo dessa premissa, este dossiê pretende contribuir para o aprofundamento do debate em torno de uma suposta "nova fase do internacionalismo operário", a partir de indagações gerais, tais como: em que medida as experiências de militância transnacional contemporâneas, com origem no ambiente de trabalho, se estariam concretizando? Tais experiências se estariam mostrando inovadoras, no sentido de superar dificuldades expe- 
rimentadas por trabalhadores nacionalmente situados? A adoção de estratégias articuladas internacionalmente significaria a paulatina superação da ênfase dada às prioridades locais, ou vivenciaríamos, hoje, uma mera adição de interesses circunscritos combinados?

Orientado por tais questionamentos, este dossiê é iniciado com um estudo de Maurício Rombaldi e Kimi Tomizaki, que examina o processo de engajamento militante transnacional a partir das particularidades do envolvimento de sindicalistas brasileiros na construção de uma "agenda global" de defesa dos direitos dos trabalhadores. Por meio da análise de trajetórias de sindicalistas metalúrgicos brasileiros, os autores tratam das condições sociais de acesso a organizações sindicais internacionais, para discutir como a militância, no plano global, tem se convertido em um caminho, até então improvável, para lideranças nacionais. O exame dos dados coletados indica que as trajetórias sindicais internacionais foram potencializadas e têm se sustentado sobre a articulação entre um conjunto de capitais e habitus militante específicos, e uma série de variáveis de caráter objetivo, particulares do caso brasileiro.

No artigo seguinte, Ruy Braga e Joana Marques comparam a formação do precariado pós-fordista no Brasil e em Portugal, a partir da análise dos padrões de proletarização do trabalho artístico e de sua relação com diferentes trajetórias de ação coletiva. Com isso, evidenciam os impasses enfrentados pelo movimento dos trabalhadores precários para transnacionalizar suas formas de ação coletiva. No caso brasileiro, tratam da mobilização pelo desenvolvimento de políticas públicas para a cultura, que conduziu à conquista do programa de Fomento ao Teatro. Em Portugal, examinam a criação do sindicato-movimento Cena, em um contexto marcado pela adoção de políticas de austeridade em escala europeia. Os limites da transnacionalização das reivindicações desses grupos de trabaIhadores são problematizados à luz da ideia presente em estudos "neo- 
polanyianos" do trabalho, segundo a qual o processo de mobilização do precariado no Sul global anunciaria o advento de um contramovimento "embrionário".

Hermes da Costa reflete sobre a organização transnacional de trabalhadores por meio da análise de distintas configurações institucionais e modos de atuação, em especial, os Conselhos de Empresa Europeus (CEEs). O autor constrói seu exame a partir de conteúdos de acordos de CEEs envolvendo representantes de trabalhadores nos setores metalúrgico, químico e financeiro, bem como de entrevistas realizadas com representantes de trabalhadores nesses conselhos. O principal argumento do texto reside em afirmar que tais conselhos de empresa condensam potencialidades para a regulação das relações de trabalho e a transnacionalização da militância entre trabalhadores.

Em seu artigo, Marc-Antonin Hennebert discute como os últimos anos foram palco de uma multiplicidade de instrumentos de regulação das relações entre trabalho e capital no plano supranacional. Paralelamente às instâncias mais conhecidas de discussão e produção de normas para o mundo do trabalho, sobretudo as organizações intergovernamentais como OIT e ONU, o autor observa a criação de um conjunto de códigos de conduta empresariais que está relacionado aos debates em torno do tema da "Responsabilidade Social de Empresas" (RSE). Diante da multiplicação de mecanismos vinculados à RSE, o artigo examina, em especial, a negociação e o estabelecimento de Acordos-Marco Internacionais, e lança luz, por meio da análise dos casos de duas empresas estadunidenses, sobre as possibilidades e limites desses ajustes, com destaque para o papel dos atores sindicais para a efetivação e o sucesso de tais acordos na regulação de condições de trabalho, salários e garantia de direitos.

Encerram este dossiê o estudo de João Paulo Cândia Veiga e Katiuscia Moreno Galhera e a entrevista com o intelectual estadunidense Chris 
Tilly, realizada por Roberto Véras de Oliveira. O artigo propõe-se a debater os processos de transnacionalização da organização de trabalhadores no setor de confecção do vestuário. A partir da análise do caso da Inditex, uma holding proprietária da Zara e que corresponde a uma das maiores multinacionais da indústria têxtil, os autores argumentam que, no setor econômico em questão, a ação coletiva se dilui em arranjos institucionais compostos por iniciativas multistakeholder que acabam por promover processos decisórios de cúpula, sem a influência e a participação dos trabalhadores representados em organizações sociais - exatamente aqueles que vivenciam a precarização e a violação de direitos sociais e trabalhistas na cadeia do vestuário. Por fim, a entrevista com o professor Tilly complementa de forma precisa o conjunto de artigos apresentado neste dossiê. Tal material, que aborda uma importante trajetória acadêmica internacional orientada a estudos sobre o mundo do trabalho e ao engajamento político, certamente permitirá aos leitores refletir sobre o modus operandi científico e a sua relação com os novos campos de pesquisa no âmbito do trabalho e da ação coletiva.

Os artigos que compõem essa edição, originados de múltiplos enfoques teóricos e empíricos, buscam, portanto, contribuir para a articulação de perspectivas voltadas à análise: (i) das condições sociais de circulação política de sindicalistas, observadas por meio do uso que estes fazem de capitais simbólicos, sejam eles políticos, culturais ou escolares; (ii) das conexões e dos desencontros entre agendas sindicais locais e internacionais; (iii) das possibilidades e dos limites da ação transnacional conduzida por organizações sindicais, sobretudo em torno de acordos internacionais constituídos em diferentes países e continentes; e, por fim, (iv) das formas como se desenvolvem as alianças estabelecidas pelos atores diretamente relacionados ao "chão de fábrica" para a mediação de disputas e conflitos no ambiente global. Com este panorama, esperamos que os textos trazi- 
dos aqui sirvam para estimular novos debates sobre o futuro do sindicalismo e o potencial de organização dos trabalhadores e trabalhadoras em defesa de condições de trabalho justas.

Maurício Rombaldi é Doutor em Sociologia pela Universidade de São Paulo e Professor Adjunto da Universidade Federal da Paraíba (UFPB).

$\triangle$ Mmauricio.rombaldi@gmail.com

Kimi Aparecida Tomizaki é Doutora em Educação pela Universidade Estadual de Campinas e Professora de sociologia na FE/USP, junto ao Departamento de Filosofia e Ciências da Educação (EDF) e ao Programa de Pós-graduação em Educação. $\triangle$-kimi.tomizaki@gmail.com

\section{Referências}

1. ANNER, M. Determinantes Industriais da Solidariedade Transnacional: política intersindical global em três setores. Estudos Avançados, 18 (81), 2014.

2. ANTUNES, R. A sociedade da terceirização total. Revista da ABET, v. 14, n. 1, jan-jun 2015.

3. BURAWOY, M. From Polanyi to Pollyanna: the false optimism of global labor studies. Global Labour Journal, v. 1 (2), 2010.

4. CHESNAIS, F. A mundialização do Capital. São Paulo, Xamã, 1996.

5. GRAY, C. W. Metalúrgicos sem fronteiras: Building a Global Union at Gerdau. Tese de doutorado, Cornell University, ago 2009.

6. EVANS, P. National Labor Movements and Transnational Connections: Global Labor's Evolving Architecture Under Neoliberalism. IRLE Working Paper, n. 11614. 2014.

7. KEIDA, M. S. Globalizing Solidarity: explaining differences in U.S. Labor Union Transnationalism. Dissertação, Miami University, Oxford, OH, 2006.

8. LÖWY, M. Internacionalismo hoje: um fio de continuidade. Teoria e Debate, n. 8, out-dez 1989.

9. ROMBALDI, Maurício. Internacionalização do sindicalismo no Brasil: um estudo sobre os setores metalúrgico e de telecomunicações. Tese de doutorado, São Paulo, USP, 2012. 
10. ROMBALDI, Mauricio. A Copa de 2014 e os trabalhadores da construção: estratégias globais, mobilizações locais. Revista da ABET, v. 13, n. 2, jul-dez 2014. 11. ROMBALDI, Mauricio. Diferentes ritmos da internacionalização sindical brasileira: uma análise dos setores metalúrgico e de telecomunicações. Caderno CRH, Salvador, v.29, n.78, pp. 535-551, set/dez. 2016.

12. SCHOLTE, Jan Aart. Global Capitalism and the State. International Affairs, v. 73, n. 3, jul 1997, p. 427- 452.

13. STANDING, Guy. O Precariado: a nova classe perigosa (cap. 1). Belo Horizonte: Autêntica, 2013.

14. SYLVER, Berverly J. Forças do Trabalho: movimento de trabalhadores e globalização desde 1870. São Paulo, Boitempo, 2005.

15. TOMIZAKI, Kimi. Internacionalismo operário e socialização política de dirigentes sindicais. In: CANÊDO, Letícia; TOMIZAKI, Kimi; GARCIA Jr., Afrânio. (Org.). Estratégias educativas das elites brasileiras na era da globalização. 1ed. São Paulo: Hucitec Editora/FAPESP, 2013, pp. 91-107.

Recebido: 15.05.2017

Aceito: 22.05.2017 